\title{
DENIS MARICOURT, Figures de l'éclectisme dans la seconde moitié du XVIII siècle
}

\section{Davide Monda}

\section{(2) OpenEdition}

\section{Journals}

\section{Edizione digitale}

URL: http://journals.openedition.org/studifrancesi/33172

DOI: 10.4000/studifrancesi.33172

ISSN: 2421-5856

\section{Editore}

Rosenberg \& Sellier

\section{Edizione cartacea}

Data di pubblicazione: 1 décembre 2005

Paginazione: 640

ISSN: 0039-2944

\section{Notizia bibliografica digitale}

Davide Monda, «DENIS mARIcourt, Figures de l'éclectisme dans la seconde moitié du XVIII' siècle», Studi Francesi [Online], 147 (XLX | III) | 2005, online dal 01 novembre 2015, consultato il 19 avril 2021. URL: http://journals.openedition.org/studifrancesi/33172 ; DOI: https://doi.org/10.4000/studifrancesi. 33172

Questo documento è stato generato automaticamente il 19 avril 2021.

\section{(c) (i) (9)}

Studi Francesi è distribuita con Licenza Creative Commons Attribuzione - Non commerciale - Non opere derivate 4.0 Internazionale. 


\title{
DENIS MARICOURT, Figures de l'éclectisme dans la seconde moitié du XVIII siècle
}

\author{
Davide Monda
}

\section{NOTIZIA}

DENIS MARICOURT, Figures de l'éclectisme dans la seconde moitié du XVIII siècle, Paris, Honoré Champion, 2003, pp. 289.

1 Nel corso del XVIII secolo, si assiste al diffondersi di una vera e propria passione per le sintesi, che miravano in primis et ante omnia ad unificare e armonizzare i saperi e, in qualche misura a conciliare le diversità. Il proposito dell'informatissimo, interessante, avvincente studio di Denis Maricourt è proprio quello di ritrovare tale attitudine nei diversi ambiti della vita culturale europea, in un arco cronologico che coincide all'incirca con la seconda metà del secolo. Un esempio fondamentale è costituito senza dubbio dalla personalità inquieta e poliedrica di Denis Diderot che, nel 1755, s'avvale per la prima volta, nella lingua francese, del termine "éclectisme", e ne fa oggetto di un articolo del quinto volume dell'Enciclopedia; così, questa parola che, in origine indicava una scuola e un metodo filosofico - tutto sommato minori - apparsi ad Alessandria verso la fine del II secolo, viene ora impiegata dal grande pensatore francese per definire il "filosofo ideale", anche sulla scorta, peraltro, degli orientamenti espressi in un'opera fortunata di Jacob Brücker (Historia critica philosophiae; 1742-47), secondo il quale l'eclettismo era una disposizione della mente caratteristica della filosofia moderna. Richiamando i dati della storia antica, Diderot - scrive fra l'altro lo studioso «rappelait à sa manière combien les entreprises des éclectiques ont souvent avorté à cause de l'obcurantisme des autorités. Il rappelait aussi combien les vrais philosophes avaient vécu depuis toujours dans un état de danger permanent» (p. 18). Maricourt focalizza la propria indagine, come s'è detto, dalla metà del Settecento in avanti, 
periodo che considera il momento cardine in cui filosofi, scienziati e teorici dell'arte «interrogèrent la raison même des systèmes qu'ils avaient bâtis» (p. 22). Esplorando l'eclettismo nelle diverse manifestazioni della cultura illuminista, egli si propone tuttavia di limitare il proprio campo di analisi e riflessione a testi "suffisamment représentatifs pour exprimer le "contact" entre un être et un objet multiple, la situation singulière où un être est intéressè par l'objet inclassable. En outre, ce «contact» ou cette «expérience» doit pouvoir s'observer dans des écrits de nature différente, dans un article encyclopédique ou dans un roman libertin, dans une «histoire philosophique», un manuel de conversation autant que dans un récit de voyage ou une autobiographie» (p. 22).

2 Il volume si articola quindi in capitoli dedicati, rispettivamente, al "poligrafo" - ossia all'esigenza pluridisciplinare degli enciclopedisti - alla storia enciclopedica del mondo coloniale (Raynal). all'avventuriero, «un personnage en quète de la totalité du monde» (p. 105), che si manifesta mirabilmente nell'ormai classica Histoire de ma vie di Giacomo Casanova. La brillante ricognizione di Maricourt che prosegue con l'esame delle figure letterarie del "roman du libertinage", si sofferma su una figura di eclettico che per lui ben sintetizza, alla fine del secolo, i caratteri dei protagonisti dei romanzi precedenti: «Le personnage de Faublas créé par Louvet de Couvray en 1787 (Les amours du chevalier de Faublas) représentait en effet un homme disponible à toutes les expériences amoureuses. Le héros s'épuise à satisfaire toutes les femmes qui partagent son sentiment, il cherche à rendre compatible des amours de qualité différente. Il construit peu à peu d'implacables dilemmes qui dispersent son moi et qui déstineront les héroïnes à une fin dramatique ou tragique» (pp. 126-127). Altre parti del libro trattano, ancora, del cosmopolitismo e delle origini del "dilettantismo". La parola italiana "dilettante", entrata nella lingua francese nel 1740 con riferimento esclusivo all'"amateur" della musica italiana, si estenderà in seguito a tutte le arti, venendo a costituire l'apprezzata legittimazione d'una sorta di "demi-savoir", sempre ispirato e sostenuto, peraltro, da una passione autentica. La brillante disamina del Maricourt non manca poi di soffermarsi anche sulle diverse espressioni della "frivolité" e sull'arte della conversazione. A dispetto degl'inevitabili limiti incontrati da quello sforzo di sintesi che accomuna tanti protagonisti della cultura settecentesca, "le siècle des lumières - conclude sapientemente l'autore - nous a légué des modèles de tolérance et de comprehension entre les hommes. Et notre temps s'attache peut-etre à en retrouver la signification» (p. 262). 